The author makes no reference to the fact that food production in the developing countries is increasing substantially faster than their population. The food situation in Russia, China and Cuba he finds satisfactory. He sympathizes with the Japanese for the overcrowding and traffic congestion in their cities; it has not occurred to him that these could be cured by decentralization.

Subject to the above substantial qualifications, this is an interesting book, containing much information on food, agriculture, geography, hydrology and so on.

Colin Clark

${ }^{1}$ Ceres, July-August 1971.

${ }^{2}$ Economic and Political Weekly, Bombay, September 30, 1972.

${ }^{3}$ Gopalan, Am. J. clin. Nutr., January 1970.

\section{Topics in Zoology}

Evolutionary Biology. Edited by Th. Dobzhansky, M. K. Hecht and Wm C. Steere. Vol. 6. Pp. xiii +445 . (Appleton Century Crofts: New York, October 1972.) $\$ 19.95$.

FEw workers can have provided basic contributions to the guiding principles and knowledge of as many branches of zoology as has Dr George Simpson. This volume is dedicated to him and contains papers from eighteen workers in the fields in which he carried out his own researches-evolution, zoogeography, palaeontology and taxonomy.

Williams contributes an extremely penetrating and thought-provoking study of the zoogeography of the Anolis lizards of the West Indies. $\mathrm{He}$ first suggests three "rules" based on the work of Schoener, which predict the sizes of Anolis species. He then shows that these results can be used to reconstruct the sequence of arrival of the eleven species in Puerto Rico, and that this sequence is confirmed by studies of their phyletic relationships.

In an enjoyable style, Gould discusses the controversy as to whether the Lower Liassic Gryphaea species show a trend to increased tightness of coiling. He notes that in fact there is no evidence that any individuals were unable to open their shell, and his analysis of the data shows that there was no increase in coiling but merely an increase in size.

Three papers consider the relationships between palaeontological data, continental drift and palaeogeography. As Colbert shows, the discovery of the hippo-like reptile Lystrosaurus in Antarctica is strong evidence for a Triassic Pangaea, while McKenna demonstrates that comparisons of the mammal faunas of North America, Europe and Asia in the early Tertiary make simple sense when added to recent studies of the history of the connexions of these areas. Finally, Hoffstetter suggests that the easiest solution to the problem of the relationship between the South American and African rodents and monkeys is direct early Tertiary migration to South America across a then-narrower South Atlantic.

The evolutionary and phyletic significance of character complexes is discussed in several papers. McDowell suggests a series of adaptive stages in the evolution of tongue structure in lizards, and their significance in the problem of the origin of snakes. MacIntyre discusses the morphology of the petrosal of Late Cretaceous mammals and recognizes in them a primitive pattern which he terms "trisulcate". Romer gives an integrated account of his view that the special myological, embryological and neurological aspects of the pharyngeal region of vertebrates are relics of its importance in filter-feeding in early vertebrate history.

Several authors discuss aspects of human evolution. For example, Washburn compares the indication of different types of data on human evolution, while Neal and Schull note how little is known on the important subject of the different fertility of different races and populations of man. Lewontin presents the first estimate of the pattern of human variation, and obtains the remarkable result that only $6.3 \%$ is interracial, and more than $85 \%$ is not merely inter-racial but is contained within populations.

The levels of significance and interest of the papers in the volume seem to be well above average, and reflect the respect and affection with which Simpson is regarded by his fellows.

BARRY COX

\section{Calibration Statistics}

Uncertainty, Calibration and Probability: The Statistics of Scientific and Industrial Measurements. By C. F. Dietrich. Pp. xii +411. (Adam Hilger: London, May 1973.) $£ 18$.

There is no doubt of the need for a book on the statistical aspects of calibration. This privately published venture is, however, unlikely to prove to be that book. The greater part of the space is taken up with clearly drafted and beauti. fully printed derivations of basic statistical thinking which have been known for a long time and by now could be taken as definitive for use in a particular context. This aspect is supported by absence in the bibliography of references to the statistical journal literature of the last decade: for example, the work of Grubbs, Krutchkoff, Hahn and Thompson in the instrumentation and industrial field and Berkson in the biomedical field. For the quite different field of model calibration, for example, transportation projects and macro-econometrics, there is a separate literature but which is still part of the statistical approach to calibration. However, the sub-title of this book may relieve the author of respunsibility for these latter aspects. What is required is a treatment of the whole field of calibration problems so as to show the unified statistical approach to their understanding and resolution.

W. R. BUCKLAND

\section{On Foetal Growth Rate}

On Fetal Growth Rate: Its Variations and Their Consequences. By Margaret Ounsted and Christopher Ounsted. Pp. xii +204. (William Heinemann: London; J. B. Lippincott: Philadelphia, 1973.) £3.60.

THIS is a useful book. It contains careful thought and represents a personal dedication to the study of foetal development. Much of present knowledge is summarized, and the authors present results from their own detailed study.

The following are some of the topics covered. The social and biological factors related to birth weight; the construction of birth weight standards; the development of the placenta; the results of breeding experiments in other mammals; familial patterns of birth weight; perinatal mortality and morbidity related to birth weight; neonatal and postnatal development patterns. There is a chapter which discusses possible theoretical mechanisms determining foetal development and a final chapter pointing a way to practical developments and further research.

The book, however, has some weaknesses. To begin with, the title is unfortunate. What the authors actually discuss is weight at birth and not rate of weight growth. A further confusion is created by calling the standards of birth weight for length of gestation, "growth" standards. This implies that, for example, the (intrauterine) weight distribution at 40 weeks of gestation of those babies born at 43 weeks is identical with the birth weight distribution of babies born at 40 weeks - which is almost certainly not true.

There is also a problem resulting from the basic design of the authors' own study. They chose three groups, large for dates (LFD), small for dates (SFD) and a random control group ; groupings which are relatively inefficient at predicting the risks of perinatal mortality. For example, Rantakallio ${ }^{1}$ shows that perinatal mortality rates vary with birth weight but relatively little with gestation. Yet in their final recommendations the authors advocate presentation of perinatal mortality rates by the LFD and SFD classifications-a clearly inefficient procedure. Both Rantakallio and Butler and Alberman ${ }^{2}$ show that at $2,500 \mathrm{~g}$ the perinatal mortality is about twice the average. Thus the old "rule of thumb" which treated this birth weight as a 